\title{
Vegetative Compatibility Groups and Parasexual Segregation in Colletotrichum acutatum Isolates Infecting Different Hosts
}

\author{
Claudinéia Conationi da Silva Franco, Juliane Rocha de Sant’ Anna, Lúcia Jacovozzi Rosada, \\ Edilson Nobuyoshi Kaneshima, José Renato Stangarlin, and Marialba Avezum Alves De Castro-Prado
}

First, second, third, and sixth authors: Departamento de Biologia Celular e Genética, fourth author: Departamento de Ciências Básicas da Saúde, Universidade Estadual de Maringá, Avenida Colombo 5790, Maringá, PR 87020-900, Brazil; and fifth author: Centro de Ciências Agrárias, Universidade Estadual do Oeste do Paraná, Rua Pernambuco 1777, Marechal Cândido Rondon, PR 85960-000, Brazil. Accepted for publication 6 March 2011.

\begin{abstract}
Franco, C. C. S., Sant' Anna, J. R., Rosada, L. J., Kaneshima, E. N., Stangarlin, J. R., and Castro-Prado, M. A. A. 2011. Vegetative compatibility groups and parasexual segregation in Colletotrichum acutatum isolates infecting different hosts. Phytopathology 101:923-928.

Heterokaryosis is an important mechanism which provides genetic variability increase in filamentous fungi. In order to assess the diversity of vegetative compatibility reactions existing among Colletotrichum acutatum isolates derived from different hosts, complementary nit mutants of each isolate were obtained and paired in all possible combinations. Vegetative compatibility groups (VCG) were identified among the isolates according

contained four members, and four VCGs $(1,4,5$, and 7) contained a single one. This study shows, for the first time, the isolation and the parasexual segregation of a heterozygous diploid sector derived from the heterokaryon formed with nit mutants from VCG-6. Diploid, named DE-3, showed nit+ phenotype and growth rate similar to the parental wild isolate. When inoculated in the presence of the haploidizing agent benomyl, the diploid strain produced parasexual haploid segregants exhibiting the nit phenotypes of the crossed mutants. Since viable heterokaryons and diploid may be formed among vegetative compatible isolates of $C$. acutatum, this study suggests that the parasexual cycle may be an alternative source of genetic variability in $C$. acutatum isolates.
\end{abstract} to their ability to form viable heterokaryons. Seven VCGs were identified among the isolates, one of which contained isolates from different hosts. VCGs 2 and 6 contained two and three members, respectively; VCG-3
Additional keywords: anthracnose, diploid formation.
Colletotrichum Corda, anamorphic Glomerella Spauld. and H. Schrenk (sordariomycetes) comprises both plant pathogenic and saprophytic species. Pathogenic species cause typical disease symptoms, known as anthracnose, characterized by sunken necrotic lesions that produce orange conidial masses under favorable environmental conditions (14,36). Anthracnose has been reported to be the preharvest and postharvest cause of severe financial loss to crops in tropical, subtropical, and temperate regions. The disease may occur on leaves, stems, and fruit of a wide range of host plants, such as strawberry (Fragaria $\times$ ananassa) (12,13), almond (Prunus dulcis) (1), anemone (Anemone coronaria) (16), and citrus (Citrus spp.) (42).

Whereas many species of Colletotrichum may infect a single host, a single Colletotrichum species may infect several ones. Examples of single species of Colletotrichum affecting multiple hosts include $C$. acutatum and $C$. gloeosporioides which infect a wide range of fruit crops, such as strawberry, apple, and avocado $(2,12,14,18)$.

The characterization of Colletotrichum species which cause disease epidemics is crucial for developing and implementing effective management strategies. While traditional methods are not always adequate for reliable differentiation among Colletotrichum species, the use of molecular techniques, such as polymerase chain reaction (PCR) methods, using DNA speciesspecific primers designed for the taxonomic identification of Colletotrichum species, has provided new insights into the

Corresponding author: M. A. A. Castro-Prado; E-mail address: maacprado@uem.br

doi:10.1094/PHYTO-12-10-0327

(C) 2011 The American Phytopathological Society differentiation of the species infecting a variety of crops $(2,36,39)$.

Vegetative compatibility grouping is an important tool extensively employed for the analysis of fungal populations of $\mathrm{Col}$ letotrichum species, including $C$. lindemuthianum from commonbean, $C$. gloeosporioides from almond, and C. acutatum from strawberry $(9,13,20,30)$. Vegetative compatibility phenotypes are naturally occurring genetic markers of phytopathogenic fungi controlled by the rigid system of vegetative (or heterokaryon) incompatibility (31). Control is mediated by vegetative self/ nonself recognition, impairing the formation of viable heterokaryons after the cell fusion events or anastomosis. Heterokaryons, the coexistence of different nuclear types in a common cytoplasm, however, are formed only by compatible isolates, i.e., strains genetically similar to vic (for vegetative incompatibility) or het (for heterokaryon incompatibility) genes. Such compatible strains are classified as members of the same vegetative compatibility group (VCG) $(23,32)$. On the other hand, isolates that differ at one or more vic or het loci are named incompatibles and programmed cell death is triggered when the cells of incompatible strains fuse $(7,9,40)$.

Genetically distinct haploid nuclei inside the heterokaryon mycelium weld into each other and originate heterozygous diploid nuclei. The latter give rise to paternal haploids or recombinants through successive processes of mitotic chromosome nondisjunction $(4,5,28,29)$.

Since heterokaryosis is an important mechanism which provides genetic variability increase in filamentous fungi $(25,30,41)$, the purpose of the present study is first to assess the diversity of vegetative compatibility reactions existing among $C$. acutatum isolates infecting strawberry, guava, Tahiti lime, sweet orange, peach, and green pepper; and second, to obtain heterozygous 
diploid sectors by employing genetically complementary nit mutants, i.e., mutants that do not reduce nitrate.

\section{MATERIALS AND METHODS}

Fungal isolates and media. Isolates of $C$. acutatum employed in this study were obtained from different host plants with anthracnose symptoms: strawberry (Fragaria $\times$ ananassa), Tahiti lime (Citrus latifolia), sweet orange (Citrus sinensus), peach (Prunus persica), green pepper (Capsicum annuum), and guava (Psidium guajava) (Table 1). The reference isolates, CGA ( $C$.

TABLE 1. Host plants, geographic location, molecular characterization, and vegetative compatibility groups (VCG) of Colletotrichum isolates employed in current study

\begin{tabular}{|c|c|c|c|c|c|}
\hline Isolate & Host plant & Location & Tissue & $\begin{array}{c}\text { Molecular } \\
\text { characterization }^{\mathrm{a}}\end{array}$ & VCG \\
\hline A-1 & Strawberry & São Paulo & Fruit & C. acutatum & 1 \\
\hline$A-2$ & Strawberry & Paraná & Fruit & C. acutatum & 2 \\
\hline B & Tahiti lime & São Paulo & Fruit & C. acutatum & 2 \\
\hline $\mathrm{C}-1$ & Sweet orange & São Paulo & Flower & C. acutatum & 3 \\
\hline $\mathrm{C}-2$ & Sweet orange & São Paulo & Fruit & C. acutatum & 3 \\
\hline $\mathrm{C}-3$ & Sweet orange & São Paulo & Flower & C. acutatum & 3 \\
\hline $\mathrm{C}-4$ & Sweet orange & São Paulo & Fruit & C. acutatum & 3 \\
\hline D-1 & Peach & São Paulo & Fruit & C. acutatum & 4 \\
\hline D-2 & Peach & São Paulo & Fruit & C. acutatum & 5 \\
\hline E-1 & Green pepper & São Paulo & Fruit & C. acutatum & 6 \\
\hline E-2 & Green pepper & São Paulo & Fruit & C. acutatum & 6 \\
\hline \multirow[t]{2}{*}{ E-3 } & Green pepper & Rio de & & & \\
\hline & & Janeiro & Fruit & C. acutatum & 6 \\
\hline $\mathrm{F}$ & Guava & São Paulo & Fruit & C. acutatum & 7 \\
\hline $\mathrm{CAA}^{\mathrm{b}}$ & Sweet orange & São Paulo & Fruit & C. acutatum & 3 \\
\hline $\mathrm{CGA}^{\mathrm{b}}$ & Peach palm & Paraná & Fruit & C. gloeosporioides & - \\
\hline
\end{tabular}

a Molecular characterization using polymerase chain reaction methods with DNA species-specific primers.

${ }^{\mathrm{b}}$ Reference isolates. gloeosporioides) from peach palm (Bactris gasipaes) and CAA (C. acutatum) from sweet orange (Citrus sinensus), were donated, respectively, by D. J. Tessmann and by W. Mário de Carvalho Nunes (Departamento de Agronomia, Universidade Estadual de Maringá PR, Brazil). Culture stocks were maintained at $25^{\circ} \mathrm{C}$ in amber flasks with Basal medium (BM). Complete medium (CM) and BM have been previously described by Castro-Prado et al. (9).

Isolation of nit mutants. Mycelium plugs, $5 \mathrm{~mm}$ in diameter, were removed from the periphery of $C$. acutatum colonies cultivated in $\mathrm{CM}$ and transferred to petri plates with $\mathrm{BM}+\mathrm{NaNO}_{3}$ $(0.2 \%)+\mathrm{KClO}_{3}(3.5$ to $4.0 \%)$. Plates were incubated at $22^{\circ} \mathrm{C}$ for 15 days. Fast-growing sectors emerging from the restricted colonies were transferred to petri plates containing $\mathrm{BM}$ and incubated at $22^{\circ} \mathrm{C}$ for 5 days. Colonies exhibiting a thin and expanding mycelium in $\mathrm{BM}$ were classified as unable to use nitrate as a nitrogen source (nit mutants). In order to determine the phenotypes of nit mutants, they were transferred to petri plates with BM, supplemented with different nitrogen sources: sodium nitrate $(0.2 \%)$, potassium nitrite $(0.085 \%)$, hypoxanthine $(0.01 \%)$, and ammonium tartrate $(0.092 \%)$. Plates were incubated at $22^{\circ} \mathrm{C}$ for 4 to 10 days, and nit mutants were characterized in three distinct phenotypic classes: nit1 (nitrate nonutilizing), Nit3 (nitrate and nitrite nonutilizing), and NitM (hypoxanthine and nitrate nonutilizing; deficient in the molybdenum cofactor) (6).

Obtaining heterokaryons and diploids. Mycelium plugs $(5 \mathrm{~mm})$ of complementary nit mutants were paired equidistantly apart (approximately $1.0 \mathrm{~cm}$ ) in petri dishes containing $\mathrm{BM}+$ $\mathrm{NaNO}_{3}$. After 12 to 30 days of incubation at $22^{\circ} \mathrm{C}$, prototrophic heterokaryon growth was observed in the contact area of the paired mutants (Fig. 1A). When a sterilized coverslip was placed between the two mutant colonies at the interaction zone, no prototrophic growth occurred (Fig. 1B). The need for physical contact between the pairing mutants for heterokaryon formation was thus indicated. Fast-growing sectors, suggestive of possible
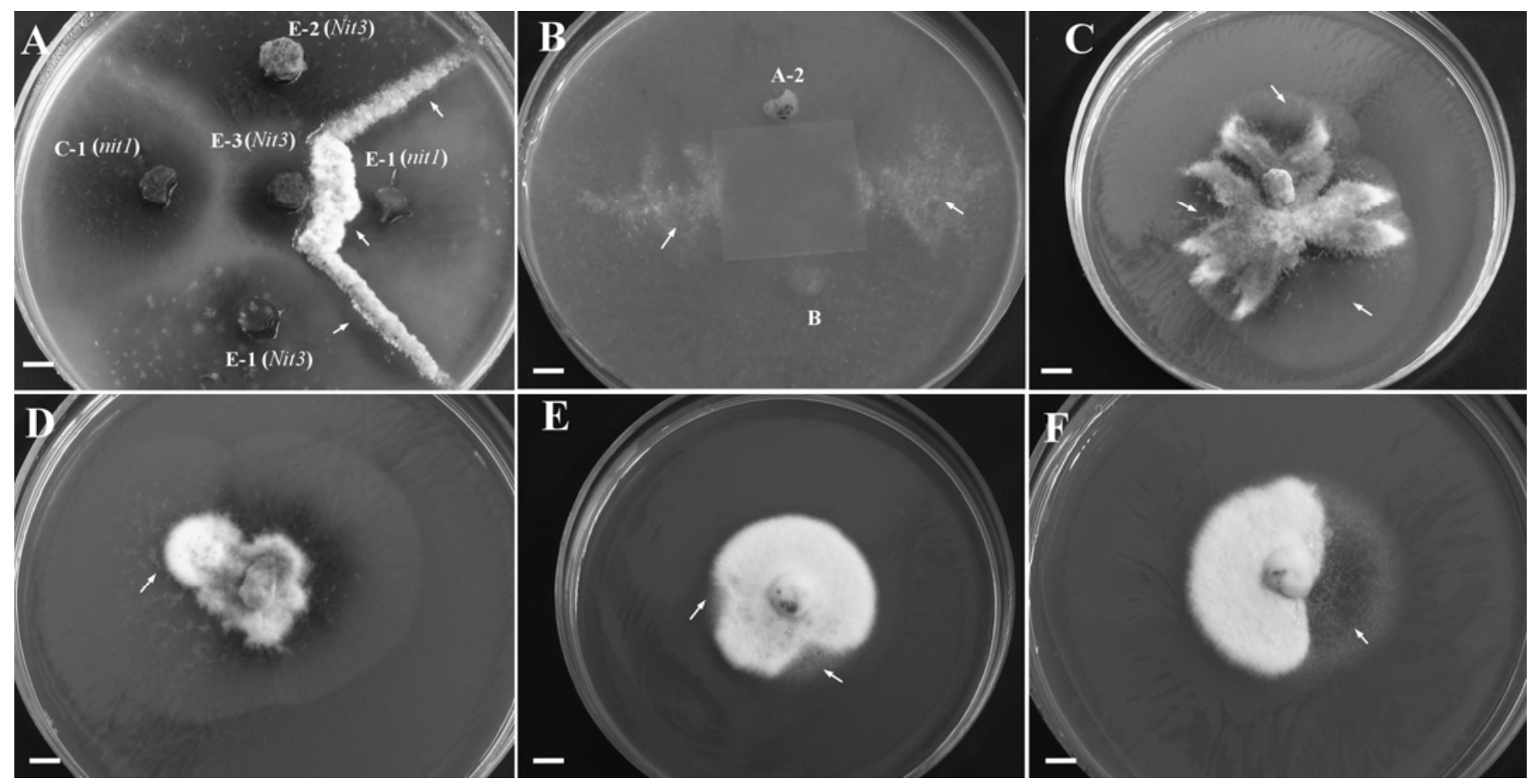

Fig. 1. A, Pairing of complementary nit mutants of the isolates from green pepper (E-1 to E-3) and sweet orange (C-1). Heterokaryons (arrows) were formed only between vegetative compatible isolates. B, Pairing between Nit3 (A-2) and nit1 (B) mutants, respectively, from strawberry and Tahiti lime, separated by a coverslip. Heterokaryons (arrows) did not occur beneath the coverslip which impairs direct contact between the pairing mycelia. C, Heterokaryotic colony [E-1 (Nit3)/E-2 (nit1)] showing mitotic segregation of the crossed nit mutants (arrows). D, Heterokaryotic colony showing a fast-growing sector (arrow). E, Diploid segregant (DE-3) showing mitotic segregation of the crossed nit mutants (arrows) in $\mathrm{BM}+\mathrm{NaNO}_{3}$. F, Unstable diploid segregant $(\mathrm{DE}-3)$ growing in $\mathrm{BM}+\mathrm{NaNO}+$ benomyl. Bar $=3.0 \mathrm{~mm}$. 
diploidy, may arise spontaneously when the heterokaryons are growing in $\mathrm{BM}+\mathrm{NaNO}_{3}$. Whereas the heterokaryotic colonies are macroscopically compact, irregular (Fig. 1C), and slowgrowing, the diploid ones are homogeneous, morphologically distinct from the heterokaryon (Fig. 1D to F), and have a growth rate similar to wild-type isolates. When growing in the presence of benomyl, the haploidizing agent, the diploid colonies produce mitotic sectors exhibiting the auxotrophic phenotypes of the parental strains. Putative diploids derived from heterokaryons were isolated and transferred to $\mathrm{BM}+$ benomyl $(0.5 \mu \mathrm{g} / \mathrm{ml})$ to detect the presence of auxotrophic sectors (or parental segregants). All experiments were repeated at least three times.

Vegetative compatibility grouping. The formation of a viable heterokaryon between two complementary nit mutants assigned their wild parent isolates to the same VCG.

Isolation of parasexual segregants from heterokaryon and diploid colonies. Parasexual segregants (or sectors), showing nit phenotype, were isolated directly from heterokaryon and diploid colonies grown in $\mathrm{BM}+\mathrm{NaNO}_{3}$. Mycelium plugs $(5 \mathrm{~mm})$ of parasexual segregants were later transferred to BM supplemented with different nitrogen sources (sodium nitrate, potassium nitrite, and hypoxanthine) for phenotypic characterization. Phenotypic analysis was repeated at least twice.

Genomic DNA extraction. Pure cultures of $C$. acutatum were grown in $\mathrm{CM}$ for 5 days at $25^{\circ} \mathrm{C}$. Mycelia were harvested by filtration (Whatman No. 1 filter paper) and ground to a fine powder in liquid nitrogen for DNA extraction as described by Loudon et al. (24).

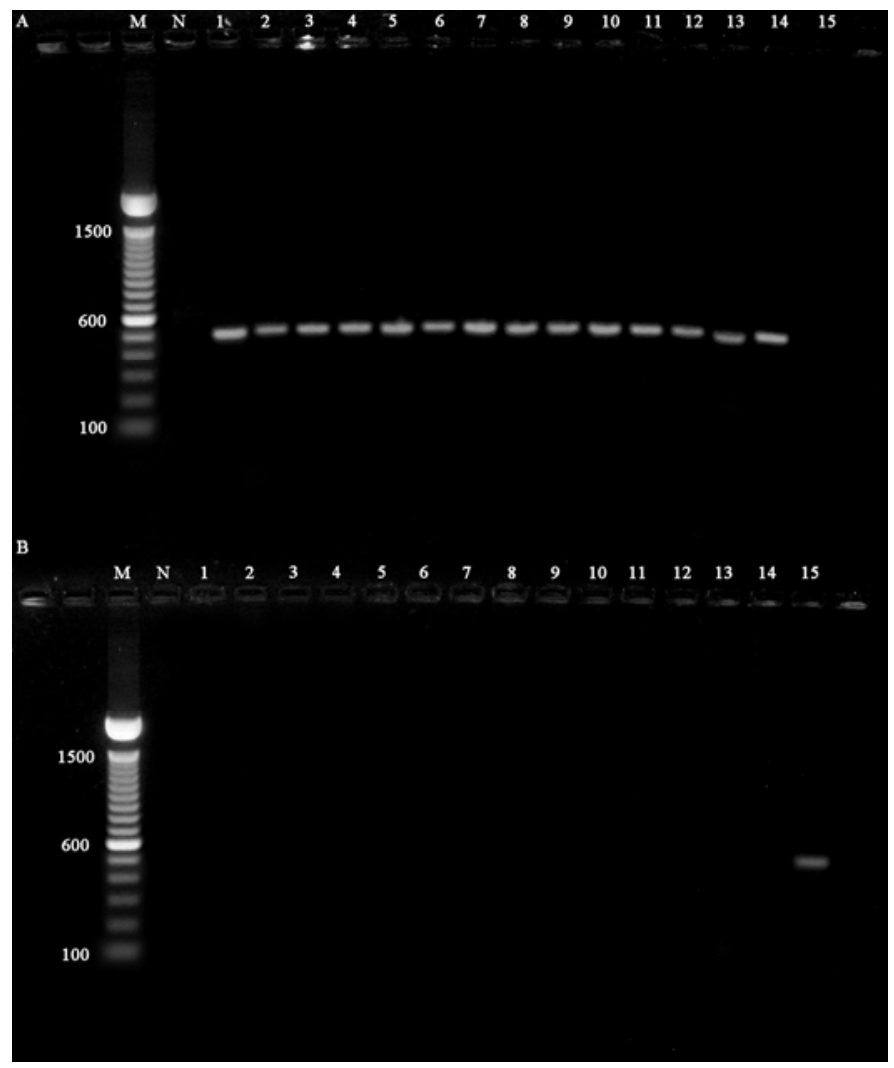

Fig. 2. Amplification products in agarose gel stained with ethidium bromide for internal transcribed spacer (ITS) ribosomal DNA. A, Taxon-specific identification of Colletotrichum acutatum (primer CaInt2 in combination with primer ITS4). B, Taxon-specific identification of C. gloeosporioides (primer CgInt in combination with primer ITS4). Lane M, molecular markers and lane $\mathrm{N}$, negative control. Lanes 1 to $13, C$. acutatum isolates, respectively, from strawberry (lanes 1 and 2), Tahiti lime (lane 3), sweet orange (lanes 4 to 7), peach (lanes 8 and 9), green pepper (lanes 10 to 12), and guava (lane 13). Lanes 14 and 15, reference isolates of $C$. acutatum and C. gloeosporioides, respectively.
PCR analysis. Species-specific PCR primers were synthesized for C. gloeosporioides (CgInt) 5'-GGCCTCCCGCCTCCGG GCGG-3' and for C. acutatum (CaInt2) 5'-GGCGCCGGCCCCG TCACGGGGG-3' from internal transcribed spacer 1 (ITS1) of the ribosomal DNA (rDNA) gene $(1,2)$. The PCR primers for taxon-specific amplification were used with the conserved primer ITS4 5'-TCCTCCGCTTATTGATATGC-3' (38). Previously characterized isolates CAA $(C$. acutatum) and CGA (C. gloeosporioides) were used as positive controls, whereas amplification reaction without DNA was employed as negative control. PCR amplification was performed in a $25 \mu \mathrm{l}$ reaction mixture containing $5 \mathrm{ng}$ of DNA; $200 \mu \mathrm{M}$ each of dATP, dCPT, dGTP, and dTTP; $500 \mathrm{mM} \mathrm{KCl} ; 100 \mathrm{mM}$ Tris- $\mathrm{HCl}(\mathrm{pH} 9.0) ; 1 \mu \mathrm{M}$ ITS4 primer; $1 \mu \mathrm{M} C g$ Int or CaInt2 primer; and $0.65 \mathrm{U}$ of Taq DNA polymerase. Temperature cycling conditions were 35 cycles of denaturation $\left(94^{\circ} \mathrm{C}\right.$, for $\left.1 \mathrm{~min}\right)$, annealing $\left(59^{\circ} \mathrm{C}\right.$, for $\left.2 \mathrm{~min}\right)$, and DNA extension $\left(72^{\circ} \mathrm{C}\right.$, for $\left.2 \mathrm{~min}\right)$. All amplified DNA products were undertaken by electrophoresis on agarose gels $(1.5 \%)$ in a Tris- $\mathrm{HCl}$ buffer, ethidium bromide $(0.4 \mu \mathrm{g} / \mathrm{ml})$, stained and photographed. All experiments were repeated at least twice.

\section{RESULTS}

Taxon-specific PCR. All isolates of $C$. acutatum obtained from strawberry, guava, Tahiti lime, sweet orange, peach, and green pepper, including the reference isolate CAA ( $C$. acutatum), produced a 490-bp fragment, following PCR with primers CaInt2 and ITS4 (Fig. 2A). On the other hand, none of the isolates, except the CGA reference isolate (C. gloeosporioides), produced an amplicon of 450-bp following PCR with the $C$. gloeosporioides-specific primers $C g$ Int and ITS4 (Fig. 2B).

VCG characterization of isolates and diploid formation. Stable nit mutants, exhibiting thin and expansive colonies in $\mathrm{BM}+$ $\mathrm{NaNO}_{3}$, were obtained from the wild $C$. acutatum isolates when grown in $\mathrm{MB}+\mathrm{NaNO}_{3}+\mathrm{KClO}_{3}$. Mutants were screened for their ability to utilize different nitrogen sources so that their phenotypes might be determined. In the case of each of the 13 wild isolates, the predominant phenotypic class was nit1 mutant followed by Nit3 and NitM mutants (Table 2).

Pairings of nit mutants derived from the 13 isolates in all possible combinations identified seven VCGs. Heterokaryons exhibiting prototrophic phenotypes and appreciably slower growth rates than those of the wild isolates in $\mathrm{BM}$ were produced in nit mutants pairings from isolates A-2 (from strawberry) and B (from Tahiti lime), which were allocated on VCG-2. Isolates from sweet orange (C-1 to C-4) and green pepper (E-1 to E-3) were allocated, respectively, on VCGs 3 and 6 , whereas isolates from strawberry (A-1), peach (D-1 and D-2), and guava (F) were allocated, respectively, on VGCs 1, 4, 5, and 7, all of which contained a single member (Table 1, Fig. 1A).

TABLE 2. Frequency of nit mutants of Colletotrichum acutatum isolates

\begin{tabular}{lccc}
\hline & \multicolumn{2}{c}{ Frequency $(\%)$ of auxotrophic nit mutants } \\
\cline { 2 - 4 } Isolates & nit1 & Nit3 & nitM \\
\hline A-1 & 61 & 25 & 14 \\
A-2 & 89 & 12 & 06 \\
B & 68 & 09 & 23 \\
C-1 & 87 & 13 & 0 \\
C-2 & 61 & 41 & 0 \\
C-3 & 75 & 19 & 06 \\
C-4 & 81 & 19 & 0 \\
D-1 & 73 & 19 & 08 \\
D-2 & 68 & 17 & 15 \\
E-1 & 71 & 17 & 12 \\
E-2 & 89 & 09 & 02 \\
E-3 & 32 & 67 & 01 \\
F & 09 & 55 & 36 \\
\hline
\end{tabular}


Although isolates A-2 and B (VCG-2) have been carrying out anastomosis among themselves (data not shown), the pairing of their nit mutants did not form viable heterokaryon in $\mathrm{BM}+$ $\mathrm{NaNO}_{3}$ when the paired mutants were separated by a sterilized coverslip (Fig. 1B). The heterokaryon formation only occurred where the mycelium of the two paired mutants came in direct contact beyond the edges of the coverslip. Results demonstrate the need for physical contact between mutant hyphae (anastomosis) for heterokaryon formation. Furthermore, heterokaryotic colonies, growing on plates containing $\mathrm{BM}+\mathrm{NaNO}_{3}$, gave rise spontaneously to parasexual auxotrophic segregants which exhibited the parental phenotypes of the crossed mutants (Table 3, Fig. 1C). Hypoxantine nonutilizing mutants, such as D-2 (NitMI) and D-2 $\left(\right.$ NitM MI $\left._{I}\right)$, exhibiting complementation in $\mathrm{BM}+\mathrm{NaNO}_{3}$ through the production of a prototrophic heterokaryon, were assumed to be nonallelic. This fact indicated the existence of multiple loci controlling the production of a molybdenumcontaining cofactor (Table 3). Similar results have been reported in other Colletotrichum species, such as $C$. lindemuthianum and C. truncatum $(9,31)$.

A fast-grown sector with nit+ phenotype was isolated from the heterokaryon formed by the pairing of Nit3 and NitM mutants derived from isolate E-3 (from green pepper) (Fig. 1D). This sector, named DE-3, produced parasexual haploid segregants in the presence of benomyl, which exhibited the parental phenotypes of the crossed mutants (Table 3, Fig. 1E and F). DE-3 was therefore characterized as a diploid segregant.

\section{DISCUSSION}

The current study evaluates the genetic relationship among $C$. acutatum isolates characterized by ribosomal DNA analysis. Thirteen $C$. acutatum isolates derived from different hosts were grouped into seven VCGs by demonstrating heterokaryosis through complementation using nit mutants. Four of the isolates belonged to the largest group VCG-3. VCGs 3 and 6 included only isolates from sweet orange and green pepper, respectively. The two isolates from peach (D-1 and D-2) were neither compatible with each other nor with any other isolates. Similarly, the isolate from guava was not compatible with the isolates from other hosts. As a rule, it was observed that isolates derived from the same host were either allocated together into the same VCG or allocated separately in distinct VCGs. An exception, however, was observed for strawberry (A-2) and Tahiti lime (B) isolates which showed

TABLE 3. Phenotypic segregation of diploid and heterokaryotic colonies formed by nit mutants of Colletotrichum acutatum

\begin{tabular}{|c|c|c|c|c|c|}
\hline \multicolumn{3}{|c|}{ Pairing of nit mutants } & \multicolumn{3}{|c|}{ Phenotypes of parasexual segregants } \\
\hline Paternal $1^{\mathrm{a}}$ & & Paternal $2^{\mathrm{a}}$ & Paternal 1 & Paternal 2 & Total $^{\mathrm{b}}$ \\
\hline A-2 (Nit3) & / & A-2 $(\text { nit } 1)^{\mathrm{c}}$ & 06 & 08 & 14 \\
\hline $\mathrm{B}($ Nit3) & / & $\mathrm{B}(\text { nitl })^{\mathrm{c}}$ & 16 & 29 & 45 \\
\hline A-2 (NitM) & l & $\mathrm{B}(\text { nitl })^{\mathrm{d}}$ & 20 & 20 & 40 \\
\hline A-2 (NitM) & / & $\mathrm{B}(N i t 3)^{\mathrm{d}}$ & 182 & 24 & 206 \\
\hline A-1 (NitM) & l & A-1 (Nit3) & 53 & 07 & 60 \\
\hline C-3 (NitM) & / & $\mathrm{C}-2(\text { nitl })^{\mathrm{d}}$ & 58 & 17 & 75 \\
\hline C-3 (NitM) & / & $\mathrm{C}-4(\text { nit } 1)^{\mathrm{d}}$ & 07 & 29 & 36 \\
\hline D-1 (NitM) & l & D-1 $(\text { nit } 1)^{\mathrm{c}}$ & 25 & 29 & 54 \\
\hline D-2 $\left(\right.$ NitM $\left._{I}\right)$ & l & D-2 $\left(\text { NitM }_{I I}\right)^{\mathrm{c}}$ & 20 & 31 & 51 \\
\hline E-1 (Nit3) & / & E-3 $(N i t M)^{\mathrm{d}}$ & 73 & 13 & 86 \\
\hline E-2 (Nit3) & I & E-3 $(N i t M)^{\mathrm{d}}$ & 45 & 09 & 54 \\
\hline E-1 (Nit3) & l & $\mathrm{E}-2(\text { nit } 1)^{\mathrm{d}}$ & 57 & 31 & 88 \\
\hline $\mathrm{F}($ Nit3) & I & $\mathrm{F}(N i t M)^{\mathrm{c}}$ & 01 & 17 & 18 \\
\hline
\end{tabular}

DE-3 (diploid segregant)

E-3 (Nit3) // E-3 (nitM) $)^{\mathrm{c}}$

16

05

21

a Mutant strain obtained from the wild isolate.

b Total number of mitotic segregants.

c Intrastrain pairing of nit mutants.

${ }^{\mathrm{d}}$ Interstrain pairing of nit mutants. vegetative compatibility between themselves and were, therefore, allocated on VCG-2. In addition, the vegetative compatibility of the isolates did not appear to be related to their geographical origin. Actually, out of the three multimember VCGs, only one (VCG-3) contained members from the same geographic area (Table 1).

Vegetative compatibility is a mechanism that controls the genetic isolation of fungal populations since vegetatively compatible isolates are expected to be similar to one another, specifically for vic or het genes $(23,32)$. Consequently, each VCG corresponds to a multilocus haplotype with respect to vegetative compatibility-controlled loci. Moreover, genotype diversity of a sample may be represented by the ratio of the number of haplotypes to sample size (10). Seven VCGs were identified among $C$. acutatum isolates, with diversity estimates of approximately 0.54 .

Studies of vegetative compatibility have been extensively used to identify subspecific genetic clones of anamorphic populations of plant pathogens, classifying them by genetic approach regardless of morphology, physiology, or pathogenicity. VCGs comprising isolates from more than one host have been previously reported in Colletotrichum species, such as $C$. acutatum and $C$. gloeosporioides, and in Verticillium dahliae, a pathogen of potato, cotton, and some vegetable crops. Israeli isolates of $C$. acutatum from strawberry and anemone showing vegetative compatibility through the production of prototrophic heterokaryons were allocated on VCG ANE-F; V. dahliae isolates from six different hosts, including potato, tomato, and peanut, were assigned on the same VCG (VCG 2A); whereas isolates from C. gloeosporioides, recovered from apple and red pepper, were allocated on the largest group, named VCG-A $(3,16,20,21)$.

Although heterokaryosis resulting from hyphal anastomosis and vegetative incompatibility barriers have been previously reported in the plant pathogenic fungi $C$. acutatum $(13,14,16)$, no diploid conidia or parasexual segregation have been detected from its heterokaryotic growth. Current research first demonstrates that prototrophic heterokaryons of $C$. acutatum produce mitotic sectors which are auxotrophs with phenotypes identical to one or to the other parental strain. Second, current study demonstrates that heterokaryons in C. acutatum may yield heterozygous diploid conidia from which haploid segregants originate. A heterozygous diploid sector, named DE-3, was spontaneously obtained from the pairing of complementary nit mutants from green pepper E-3 isolate. The DE-3 colonies were prototrophic and semi-stable, producing mitotic sectors with nit phenotype. Conidia recovered from these sectors comprised the haploid parent phenotypes. The conclusion that these sectors were haploid was supported by the observation that they were stable when growing in the presence of benomyl (data not shown).

Many fungi have a parasexual cycle in which haploid nuclei may fuse to form relatively stable diploid nuclei. Diploid cultures of mycelial fungi, which grow normally as haploids, have been proved to be important tools in conducing genetic analysis, especially in (i) the complementation and dominance testing of genetic traits; (ii) the assignment of markers to linkage groups in sexual and nonsexual fungi; and (iii) the determination of order of gene markers and estimation of the distance between them. On the other hand, the ability to form diploid cultures may be an important component of risk assessment for plant pathogen isolates used for biological control, such as Aspergillus flavus and C. gloeosporioides f. sp. hakea, especially those whose sexual cycles are rare or nonexistent in nature. Parasexual crosses between such isolates and the related natural populations could produce competitive progeny with more adapted genotypes and potentially capable to disseminate to new localities $(5,9,11$, $17,19,26,28,29)$.

During the vegetative multiplication of heterozygous diploid nuclei, somatic crossing-over (so-called parasexual recombination) and/or nondisjunctions leading to haploidization may occur, 
so that conidia eventually may be obtained which have either homozygous diploid nucleus for certain gene markers or haploid nuclei containing new combinations of the parental genetic markers. The evolutionary significance of the parasexual cycle may derive from specific advantages of both ploidy levels: the extensive vegetative diploid phase of the parasexual cycle enables fungi to accumulate recessive mutations that may be recombined and tested in haploid nuclei. The vegetative organism may consequently undergo genetic adaptation, resulting in the production of better-adapted conidia $(5,8,11,30,33,34,41)$.

The ability of $C$. acutatum isolates to form heterozygous diploid nuclei, demonstrated in present study, reveals the potential of this plant pathogen to originate undesirable conidial genetic change during its vegetative propagation. Although the life cycle of $C$. acutatum includes a sexual stage, it occurs rarely in nature $(27,35)$. However, previous studies have shown the extensive genetic diversity and heterogeneity within this species $(15,19,22)$. One hypothesis for this diversity is the occurrence of anastomosis and heterokaryosis among compatible isolates (37). Vegetative compatibility observed in current study between isolates from strawberry and Tahiti lime suggests that isolates from different hosts are potentially able to exchange genetic material.

Since viable heterokaryons and diploid may be formed between vegetatively compatible $C$. acutatum isolates (present results), and taking into account that independent isolates of $C$. acutatum may infect the same host (10), current research suggests that the parasexual process may act as a likely mechanism of genetic variability in this species.

\section{ACKNOWLEDGMENTS}

We thank N. S. Massola Júnior and L. Amorim for sending us the $C$. acutatum isolates from strawberry (A-1), sweet orange (C-1 and C-3), peach (D-1 and D-2), green pepper (E-1 to E-3), and guava (F); W. Mário de Carvalho Nunes for sending us the $C$. acutatum isolates from sweet orange (CAA and C-d); and the Conselho Nacional de Desenvolvimento Científico e Tecnológico (CNPq) for the financial support. C. C. S. Franco is the holder of a CNPq fellowship.

\section{LITERATURE CITED}

1. Adaskaveg, J. E., and Hartin, R. J. 1997. Characterization of Colletotrichum acutatum isolates causing anthracnose of almond and peach in California. Phytopathology 87:979-987.

2. Afanador-Kafuri, L., Minz, D., Maymon, M., and Freeman, S. 2003. Characterization of Colletotrichum isolates from tamarillo, passiflora, and mango in Colombia and identification of a unique species from the genus. Phytopathology 93:579-587.

3. Ahn, I. P., Kim, S., Im, K. H., and Lee, Y. H. 2003. Vegetative compatibility grouping and pathogenicity of Colletotrichum gloeosporioides isolates from different host plants. Plant Pathol. J. 19:269-273.

4. Baptista, F., Machado, M. F. P. S., and Castro-Prado, M. A. A. 2003. Alternative reproduction pathway in Aspergillus nidulans. Folia Microbiol. 48:597-604.

5. Becker, T. C. A., and Castro-Prado, M. A. A. 2006. Parasexuality in asexual development mutants of Aspergillus nidulans. Biol. Res. 39:297-305.

6. Beever, R. E., and Parkes, S. L. 2007. Vegetative compatibility groups in the fungus Cryptosporiopsis actinidiae. N.Z. J. Crop Hortic. Sci. 35:67-72.

7. Biella, S., Smith, M. L., Aist, J. R., Cortesi, P., and Milgroom, M. G. 2002. Programmed cell death correlates with virus transmission in a filamentous fungus. Proc. R. Soc. Lond. B Biol. Sci. 269:2269-2276.

8. Casela, C. R., and Frederiksen, R. A. 1994. Pathogenic variability in monoconidial isolates of the sorghum anthracnose fungus Colletotrichum graminicola from single lesions and from monoconidial cultures. Fitopatol. Bras. 19:149-153.

9. Castro-Prado, M. A. A., Queirol, C. B., Sant'Anna, J. R., Miyamoto, C. T., Franco, C. C. S., Mangolin, C. A., and Machado, M. F. P. 2007. Vegetative compatibility and parasexual segregation in Colletotrichum lindemuthianum, a fungal pathogen of the common bean. Genet. Mol. Res. 6:634-642.

10. Caten, C. E., and Newton, A. C. 2000. Variation in cultural characteristics, pathogenicity, vegetative compatibility and electrophoretic karyotype within field populations of Stagonospora nodorum. Plant Pathol. 49:219226.

11. Chacko, R. J., Weidemann, G. J., Tebeest, D. O., and Correll, J. C. 1994. The use of vegetative compatibility and heterokaryosis to determine potential asexual gene exchange in Colletotrichum gloeosporioides. Biol. Control 4:382-389.

12. Freeman, S. 2008. Management, survival strategies and host range of Colletotrichum acutatum on strawberry. Hortscience 43:66-68.

13. Freeman, S., and Katan, T. 1997. Identification of Colletotrichum species responsible for anthracnose and root necrosis of strawberry in Israel. Phytopathology 87:516-521.

14. Freeman, S., Katan, T., and Shabi, E. 1998. Characterization of Colletotrichum species responsible for anthracnose diseases of various fruits. Plant Dis. 82:596-605.

15. Freeman, S., Minz, D., Maymon, M., and Zveibil, A. 2001. Genetic diversity within Colletotrichum acutatum sensu Simmonds. Phytopathology 91:586-592.

16. Freeman, S., Shabi, E., and Katan, T. 2000. Characterization of Colletotrichum acutatum causing anthracnose of anemone (Anemone coronaria L.). Appl. Environ. Microbiol. 66:5267-5272.

17. Geiser, D. M., Pitt, J. I., and Taylor, J. W. 1998 Cryptic speciation and recombination in the aflatoxin-producing fungus Aspergillus flavus. Proc. Natl. Acad. Sci. USA 95:388-393.

18. Guerber, J. C., and Correll, J. C. 2001. Characterization of Glomerella acutata, the teleomorph of Colletotrichum acutatum. Mycologia 93:216-229.

19. Johnston, P. R., and Jones, D. 1997. Relationships among Colletotrichum isolates from fruit-rots assessed using rDNA sequences. Mycologia 89:420-430.

20. Katan, T., and Shabi, E. 1996. Vegetative compatibility among isolates of Colletotrichum gloeosporioides from almond in Israel. Eur. J. Plant Pathol. 102:597-600.

21. Korolev, N., Katan, J., and Katan, T. 2000. Vegetative compatibility groups of Verticillium dahliae in Israel: Their distribution and association with pathogenicity. Phytopathology 90:529-536.

22. Lardner, R., Johnston, P., Plummer, K., and Pearson, M. 1999. Morphological and molecular analysis of Colletotrichum acutatum sensu lato. Mycol. Res. 103:275-285.

23. Leslie, J. F. 1993. Fungal vegetative compatibility. Annu. Rev. Phytopathol. 31:127-150.

24. Loudon, K. W., Burnie, J. P., Coke, A. P., and Matthew, R. C. 1993. Application of polymerase chain reaction to fingerprinting Aspergillus fumigatus by random amplification of polymorphic DNA. J. Clin. Microbiol. 31:1117-1121.

25. Milgroom, M. G., Sotirovski, K., Risteski, M., and Brewer, M. T. 2009. Heterokaryons and parasexual recombinants of Cryphonectria parasitica in two clonal populations in southeastern Europe. Fungal Genet. Biol. 46:849-854.

26. Morris, M. J. 1989. A method for controlling Hakea sericea Schrad. seedlings using the fungus Colletotrichum gloeosporioides (Penz.) Sacc. Weed Res. 29:449-454.

27. Peres, N. A., Timmer, L. W., Adaskaveg, J. E., and Correll, J. C. 2005. Lifestyles of Colletotrichum acutatum. Plant Dis. 89:784-796.

28. Pontecorvo, G. J. 1956. The parasexual cycle in fungi. Annu. Rev. Microbiol. 10:393-400.

29. Pontecorvo, G. J., Rop, L. M., Hemmons, K. D., and Macdonald, A. W. J. B. 1953. The genetics of Aspergillus nidulans. Adv. Genet. 5:141-238.

30. Rosada, L. J., Franco, C. C. S., Sant'Anna, J. R., Kaneshima, E. N., Gonçalves-Vidigal, M. C., and Castro-Prado, M. A. A. 2010. Parasexuality in race 65 Colletotrichum lindemuthianum isolates. J. Eukaryot. Microbiol. 57:383-384.

31. Sant'Anna, J. R., Miyamoto, C. T., Rosada, L. J., Franco, C. C. S., Kaneshima, E. N., and Castro-Prado, M. A. A. 2010. Genetic relatedness of Brazilian Colletotrichum truncatum isolates assessed by vegetative compatibility groups and RAPD analysis. Biol. Res. 43:51-62.

32. Saupe, S. J. 2000. Molecular genetics of heterokaryon incompatibility in filamentous ascomycetes. Microbiol. Mol. Biol. Rev. 64:489-502.

33. Schoustra, S. E., Debets, A. J. M., Slakhorst, M., and Hoekstra, R. F. 2006. Reducing the cost of resistance: Experimental evolution in the filamentous fungus Aspergillus nidulans. J. Evol. Biol. 19:1115-1127.

34. Schoustra, S. E., Debets, A. J. M., Slakhorst, M., and Hoekstra, R. F. 2007. Mitotic recombination accelerates adaptation in the fungus Aspergillus nidulans. PLoS Genet. 3:648-653.

35. Talgo, V., Aamot, H. U., Stromeng, G. M., Klemsdal, S. S., and Stensvand, A. 2007. Glomerella acutata on highbush blueberry (Vaccinium corymosum L.) in Norway. Plant Health Prog. DOI: 10.1094/PHP-2007-0509-01-RS.

36. Talhinhas, P., Sreenivasaprasad, S., Neves-Martins, J., and Oliveira, H. 2005. Molecular and phenotypic analyses reveal association of diverse Colletotrichum acutatum groups and a low level of C. gloeosporioides with Olive anthracnose. Appl. Environ. Microbiol. 71:2987-2998. 
37. Wharton, P. S., and Diéguez-Uribeondo, J. 2004. The biology of Colletotrichum acutatum An. Jard. Bot. Madr. 61:3-22.

38. White, T. J., Bruns, T., Lee, S., and Taylor, J. 1990. Amplification and direct sequencing of fungal ribosomal RNA genes for phylogenetics. Pages 315-322 in: PCR Protocols: A Guide to Methods and Applications. M. A. Innis, D. H. Gelfand, and J. J. Sninsky, eds. Academic Press, San Diego, CA

39. Xiao, C. L., Mackenzie, S. J., and Legard, D. E. 2004. Genetic and pathogenic analyses of Colletotrichum gloeosporioides from strawberry and noncultivated hosts. Phytopathology 94:446-453.
40. Zamani, M. R., Motallebi, M., and Rostamian, A. 2004. Characterization of Iranian isolates of Fusarium oxysporum on the basis of RAPD analysis, virulence and vegetative compatibility. J. Phytopathol. 152:449-453.

41. Zeigler, R. S., Scott, R. P., Leugn, H., Bordeos, A. A., Kumar, J., and Nelson, R. J. 1997. Evidence of parasexual exchange of DNA in the rice blast fungus challenges its exclusive clonality. Phytopathology 87:284294.

42. Zulfiqar, M., Brlansky, R. H., and Timmer, L. W. 1996. Infection of flower and vegetative tissues of citrus by Colletotrichum acutatum and $C$. gloeosporioides. Mycologia 88:121-128. 